\title{
Perinatal Programming of Childhood Asthma: Early Fetal Size, Growth Trajectory during Infancy, and Childhood Asthma Outcomes
}

\author{
Steve Turner \\ Child Health, Royal Aberdeen Children's Hospital, University of Aberdeen, Foresterhill, Aberdeen AB25 2ZG, UK \\ Correspondence should be addressed to Steve Turner, s.w.turner@abdn.ac.uk \\ Received 20 June 2011; Accepted 31 October 2011 \\ Academic Editor: Kuender D. Yang \\ Copyright $\odot 2012$ Steve Turner. This is an open access article distributed under the Creative Commons Attribution License, which \\ permits unrestricted use, distribution, and reproduction in any medium, provided the original work is properly cited.

\begin{abstract}
The "fetal origins hypothesis" or concept of "developmental programming" suggests that faltering fetal growth and subsequent catch-up growth are implicated in the aetiology of cardiovascular disease. Associations between reduced birth weight, rapid postnatal weight gain, and asthma suggest that there are fetal origins to respiratory disease. The present paper first summarises the literature relating birth weight and post natal growth trajectories to asthma outcomes. Second, issues regarding the interpretation of antenatal fetal ultrasound measurements are discussed. Finally, recent reports linking antenatal measurement and growth trajectory to early childhood asthma outcomes are discussed. Understanding the nature and timing of factors which influence antenatal growth may give important insight into the antecedents of early-onset asthma with implications for interventions.
\end{abstract}

\section{Introduction}

As a rule, mammals either have a short gestation and are born in an immature condition or have a long gestation but are mature at term and can run or swim shortly after birth. One exception to this rule is Homo sapiens who has a relatively long gestation but is still immature at term. There is therefore a relatively large window of opportunity for both antenatal and early post natal exposures to positively or negatively affect human development. The respiratory system provides one example of human development spanning across antenatal and post natal periods since the airways are established before the pregnancy reaches midpoint but alveoli start to appear during the third trimester through to at least three years of age [1]. Not unsurprisingly therefore, antenatal and post natal exposures have been implicated in the causation of respiratory disease.

Describing the impact of antenatal and post natal exposures on development of the respiratory system is relatively easy after birth and methods include symptom-based questionnaires and physiological measurements. In contrast, determining the effect of antenatal exposures on the individual's respiratory wellbeing in utero is considerably more challenging. To date, birth weight has been commonly used as an index of fetal wellbeing and the assumption is that adverse exposures on the respiratory system are manifest as reduced growth. However, birth weight is the end point of nine month's growth and, as Figure 1 demonstrates, insults at different gestations might result in "catch-up growth" associated with high birth weight (outcome 1, Figure 1), normal birth weight (outcome 2, Figure 1), or low birth weight (outcome 3, Figure 1). For humans, the timing of a fetal insult and ensuing catch-up growth is not yet fully described, but the suggested growth trajectories depicted in Figure $1 \mathrm{can}$ be inferred from animal studies [2] and also observational studies in humans $[3,4]$. Growth acceleration may also (theoretically) be a primary phenomenon, that is, not a response to fetal growth failure. What is required is insight into fetal wellbeing during antenatal life and how this is relevant to post natal outcomes. Recently, longitudinal cohorts have been established which are able to link fetal ultrasound measurements made during pregnancy to post natal outcomes [4-9]. These studies are able to explore the fetal origins hypothesis, also termed developmental programming [1012 ], which proposes that "fetal undernutrition in middle to late gestation, leads to disproportionate fetal growth, 


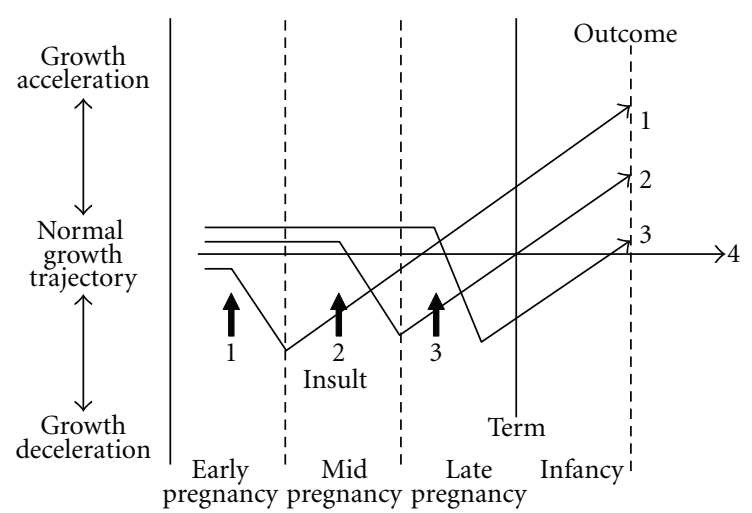

Figure 1: Schematic diagram demonstrating how growth deceleration at different gestations with resulting "catch-up growth" may result in low, normal, or high birth weight. Insult 1 in early pregnancy results in initial growth deceleration followed by growth acceleration during mid and late pregnancy and post natal life and is associated with increased birth weight (Outcome 1). Insult 2 occurs during mid pregnancy and results in growth deceleration followed by growth acceleration during later pregnancy and infancy, associated with normal birth weight (Outcome 2). Insult 3 occurs during late pregnancy leading to with low birth weight and ensuing "catch-up growth" during infancy (Outcome 3). Outcome 4 illustrates normal growth throughout pregnancy and infancy.

programs later (coronary heart) disease" [10]. The present review considers the relationship between fetal growth and childhood asthma, the latter being an example of a chronic condition where exposures in fetal life are thought to be important to aetiology. The review has three aims.

(i) To summarise recent evidence linking birth anthropometry and growth during infancy to respiratory outcomes.

(ii) To explore the potential and limitations for using fetal ultrasound measurements as an index for fetal wellbeing.

(iii) To describe the recent literature linking fetal size, fetal growth trajectories, and respiratory outcomes in later life.

\section{Birth Anthropometry and Respiratory Outcomes}

There is a considerable literature relating birth size to asthma symptoms in later life but no systematic review. There is a systematic review summarising the literature relating gestation to asthma [13] where the consensus is that a shorter gestation at delivery is associated with increased risk for the later development of asthma. For the purpose of the present article, key words "Asthma" and "Birth weight" were used in an Ovid search engine (to yield 129 abstracts) and relevant papers published since 2000 were reviewed. Publications known to the author but not identified by the search were added (see Table 1). A formal systematic review on this topic is required.
A number of themes emerge from this semistructured literature review. First, there is no consensus on the relationship between birth weight and asthma; nine studies find an inverse relationship [14-22], ten find no relationship [2332], and three find a positive relationship [33-35]. There may be an issue of power since inverse relationships are seen in large and very large study populations (median of 8071 individuals) whereas studies reporting no effect tend to be of medium size (median number of participants 3628). Second, there is more consistent evidence of increased asthma among those of low birth weight (i.e., less than $2.5 \mathrm{~kg}$ ) where there is approximately a doubling in risk for asthma; it is not clear whether this is independent of prematurity. Third, there is limited evidence of increased asthma among very heavy infants (i.e., $>4.5 \mathrm{~kg}$ ) $[33,34]$. Finally, other indices of size at birth, for example, ponderal index [30,35] (weight/length ${ }^{3}$ ), may be more closely related to asthma compared to birth weight.

Given the different growth trajectories which may converge to a given birth weight (Figure 1) it is perhaps not surprising that the relationship between birth weight and asthma is not straight-forward. Using birth weight as a "snap shot" of fetal wellbeing has its limitations and in recognition of this, post natal growth trajectory has been related to asthma.

\section{Post Natal Weight Gain, Asthma, and Lung Function}

Post natal growth trajectory may be a more accurate reflection of antenatal growth compared to birth weight; a movie picture rather than a photograph telling a story. For example, an infant born on the 9th centile for birth weight who demonstrates accelerated post natal growth and reaches the 50th centile by three months might be assumed to have had growth suppression in utero. In contrast, a similarsized infant born on the 9th centile whose post natal growth follows the 9th centile is simply marginally smaller than average and most likely grew along the 9th centile in utero. Ideally antenatal and post natal growth trajectories would be obtained to study the relationship between early growth and asthma outcomes.

What is important when understanding the relevance of the relationship between somatic and pulmonary growth is that whilst the body may be able to "catch up," the airways are established by mid pregnancy and may not be able to catch up, leaving the individual with small airways relative to body size. Proof-of-concept for dysanapsis (i.e., dissociation between somatic and pulmonary growth) comes from a cohort study of 1232 individuals from Chile study where increased gain in weight and length during infancy were associated with a modest increase in asthma symptoms at age 23-29 [36]. Studies where followup is only reported into childhood also find positive associations between weight gain during infancy and asthma risk. A cohort in Southampton reported that increased weight and adiposity (but not length) during infancy was associated with increased risk for wheeze at of age three years [7]. Paul and colleagues [37] used data collected as part of a randomised 


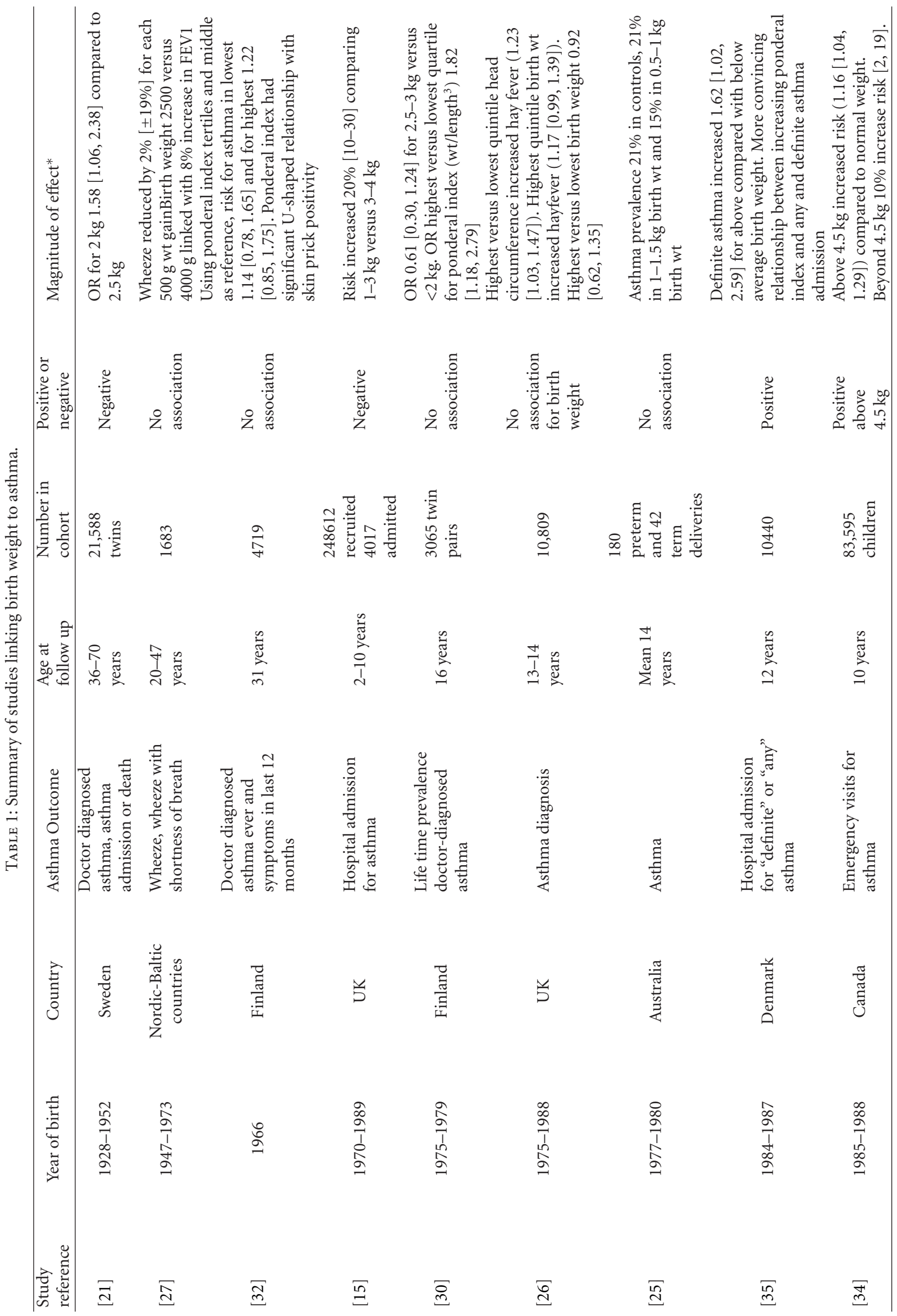




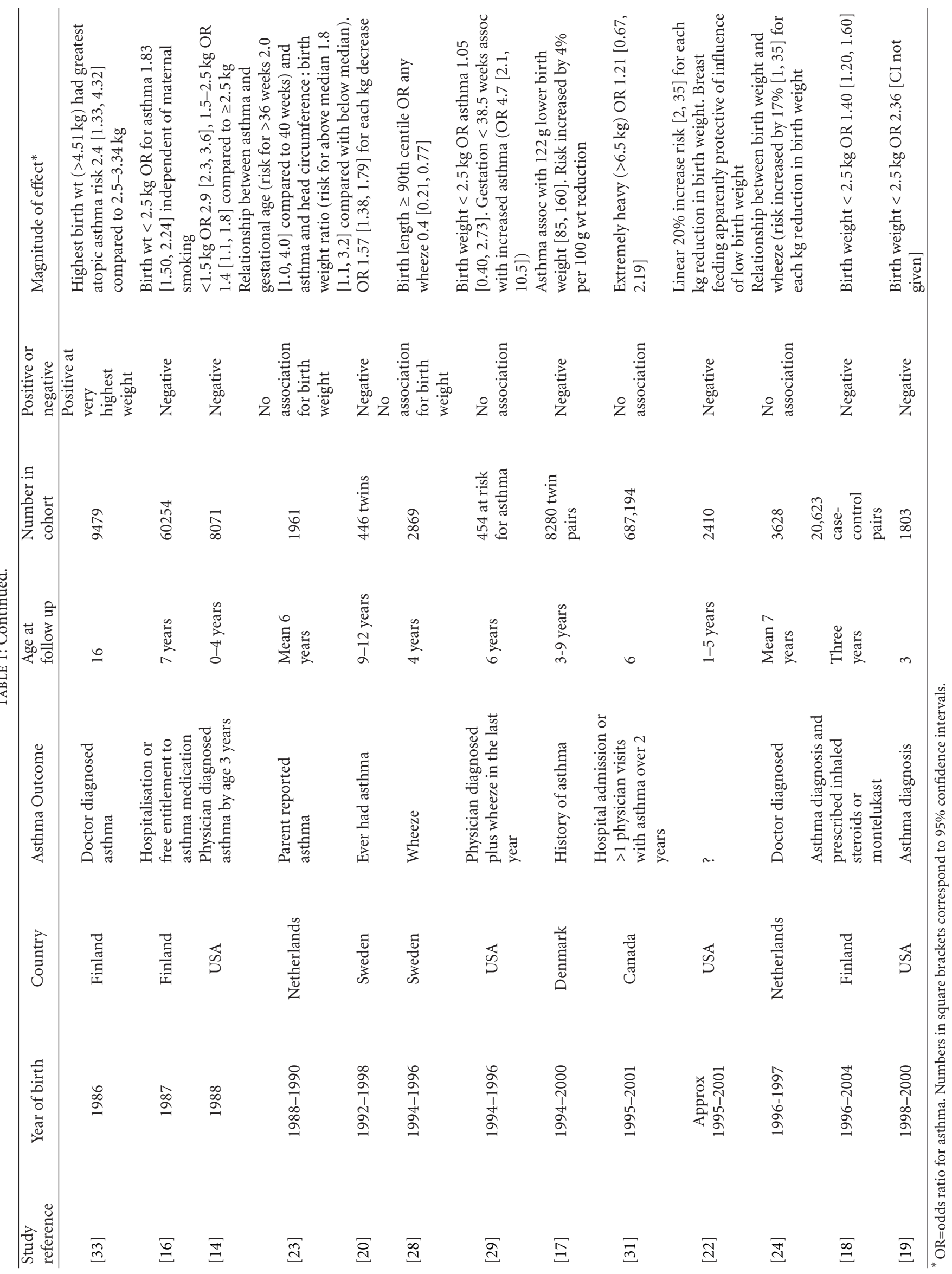


controlled trial of inhaled corticosteroids in wheezy 2-3-yearold children and related change in weight between birth and enrolment to asthma outcomes including burden of symptoms, quality of life, functional capacity, exacerbations of asthma and medication side effects. Compared with reduced growth, accelerated growth was associated with a $50 \%$ increase in exacerbations requiring prednisolone treatment (0.6/year/child versus $0.9 /$ year/child) and more than a $100 \%$ increase in unscheduled physician visits $(0.5 /$ year/child versus $1.1 /$ year/child). Although there is a relative paucity of data linking growth in infancy to asthma diagnosis and symptoms, this limited literature is entirely consistent. The literature linking weight gain and pulmonary function is less consistent.

In infancy, rapid early weight gain is associated with reduced $\mathrm{FEV}_{0.4}$ at one month [38] and reduced mid expiratory flow at the end of infancy [39] but a trend for increased mid expiratory flow at age 11 years [39]. In a large cohort study in the Avon region of UK, infants with birth weight < 10th centile who demonstrate catch-up growth had evidence of better lung function as 7-8 year olds compared to those of a similar weight who do not catch up but still lower than peers of average birth weight [40]. The improved lung function in the "catch-up" group was not significantly better than the persistently small infants despite this being a very large study population and the results could be interpreted as supporting the concept of dysanapsis or possibly indicating that catch up in somatic growth may be associated with very small degree of catch up in pulmonary growth [40].

Cohorts with followup into adulthood have demonstrated increased weight gain during infancy being associated with increased lung function in adults, that is, a reversal of the relationship seen between weight gain and lung function in infancy. For men aged 31 years, this was equivalent to a mean increase of $51 \mathrm{mLs}$ FVC for each $\mathrm{kg}$ gained and for women, mean increases of $19 \mathrm{mLs}$ FEV1 and $30 \mathrm{mLs}$ FVC [41]. In a second study increased growth during first three years was associated with increased functional residual capacity and gas transfer at 32 years of age [42] but not with altered $\mathrm{FEV}_{1}$. The transformation of the association between post natal growth and lung function from negative in infants to positive in adults is difficult to understand but might be a cohort effect, that is, the nature of the relationship has changed over time.

Findings from these epidemiological studies could be interpreted as follows.

(i) A more rapid increase in size during infancy is associated with increased risk for asthma.

(ii) A more rapid increase in size during infancy is associated with reduced lung function during infancy but marginally increased lung function during adulthood.

\section{Application of Fetal Measurements to Epidemiological Studies}

Ultrasonography provides a unique view of the developing fetus, and in many countries ultrasound examinations are

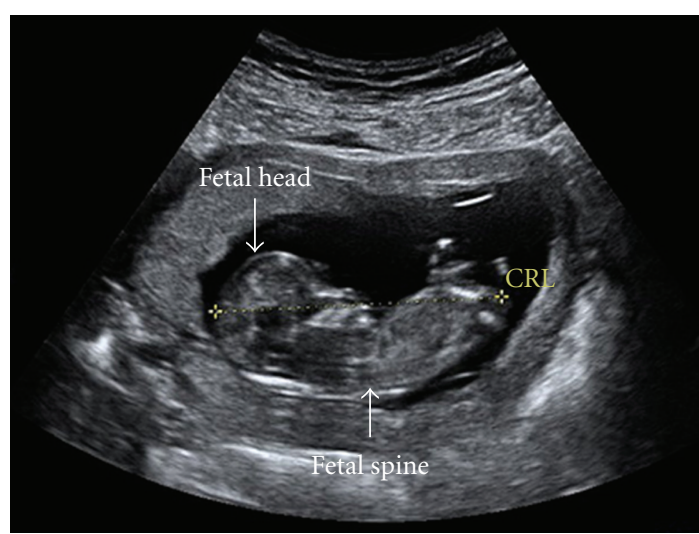

FIGURE 2: Ultrasound image of a 12-week fetus. The broken yellow line is the crown rump length $(\mathrm{CRL})$ measurement.

routinely carried out to date pregnancies in the first trimester (usually at approximately week 10) and detect congenital abnormalities during and after the second trimester (approximately week 20). The interpretation of fetal measurements in the context of post natal outcomes is not necessarily straightforward and there are a number of methodological considerations each of which apparently weaken any relationship between fetal size and later health outcomes.

First, different measurements are made at different gestations, so which measurement is "best"? Crown rump length (Figure 2) is measured in the first trimester to date a pregnancy and is known to be a very accurate predictor of gestation in the first trimester [43] but becomes more variable beyond 14 weeks [43] and other measurements are required. Second trimester fetal measurements include biparietal diameter [44], femur length [45], and abdominal girth [46] and are not routinely measured in the first trimester since the fetus is so small. Even modern ultrasound may lack precision for head, abdominal, and limb measurements in a ten-week fetus which on average measures $45 \mathrm{~mm}$ from crown to rump. At birth, weight, crown-heel length, and occipitofrontal circumference can be measured but these are not directly comparable to first and second trimester measurements. Unfortunately, there is no single "gold standard" fetal measurement which can be made throughout pregnancy. Second, even in health, fetal growth is not linear over time [47] and an apparent acceleration or deceleration may be normal. Third, in the context of fetal "stress" there is sparing of head growth at the expense of the body which leads to asymmetrical growth retardation; in the context of fetal "stress," the fetal head measurement may be within the normal range but the abdominal girth will be reduced. Fourth, as with all measurements there is an element of interobserver variability and first trimester fetal measurements, this is estimated to be approximately 10\% [48]. In epidemiological studies, the impact of factors such as nonlinear growth and intrasubject variation in measurements can be minimised by inclusion of large numbers of participants.

Finally, and perhaps most importantly, anthropometric measurements are not necessarily related to the function 
TABLE 2: Summary of asthma and allergy outcomes in the context of changing growth trajectory during early pregnancy.

\begin{tabular}{|c|c|c|c|c|c|c|}
\hline \multirow{2}{*}{ First-second trimester } & \multicolumn{3}{|c|}{ Increased rate of growth } & \multicolumn{3}{|c|}{ Reduced rate of growth } \\
\hline & Asthma symptoms & Atopy & Lung function & Asthma symptoms & Atopy & $\begin{array}{l}\text { Lung } \\
\text { function }\end{array}$ \\
\hline Southampton 3 years & & $\begin{array}{l}\text { Increased skin } \\
\text { prick positivity }\end{array}$ & & $\begin{array}{l}\text { Increased } \\
\text { nonatopic wheeze }\end{array}$ & & \\
\hline Aberdeen 5 years & Increased asthma & & $\begin{array}{l}\text { Reduced } \mathrm{FEV}_{1}, \mathrm{FVC} \\
\mathrm{FEF}_{25-75}\end{array}$ & & & $\begin{array}{l}\text { Reduced } \\
\text { FEV }_{1}\end{array}$ \\
\hline Aberdeen 10 years & Increased asthma & Increased hayfever & Reduced $\mathrm{FEF}_{25-75}$ & Increased asthma & Reduced eczema & $\begin{array}{l}\text { Reduced } \\
\text { FVC }\end{array}$ \\
\hline
\end{tabular}

TABLE 3: Summary of asthma and allergy outcomes in the context of changing growth trajectory during late pregnancy.

\begin{tabular}{|c|c|c|c|c|c|c|}
\hline \multirow{2}{*}{$\begin{array}{l}\text { Second-third } \\
\text { trimester }\end{array}$} & \multicolumn{3}{|c|}{ Increased rate of growth } & \multicolumn{3}{|c|}{ Reduced rate of growth } \\
\hline & Symptoms & Atopy & Lung function & Symptoms & Atopy & $\begin{array}{l}\text { Lung } \\
\text { function }\end{array}$ \\
\hline Southampton & & & & $\begin{array}{c}\text { Increased atopic } \\
\text { wheeze }\end{array}$ & $\begin{array}{l}\text { Increased skin } \\
\text { prick positivity }\end{array}$ & \\
\hline Aberdeen 5 years & Increased asthma* & & & & & \\
\hline Aberdeen 10 years & Increased asthma & & $\begin{array}{c}\text { Reduced } \mathrm{FEV}_{1} \text { and } \\
\text { FVC }\end{array}$ & & & \\
\hline
\end{tabular}

* Data not published but can be confirmed by the author.

of individual organ systems, for example, cardiovascular system. However, spirometry is positively correlated with anthropometric measurements in children including sitting height [49] (i.e., crown rump length) and limb length [50] (i.e., femur length) and therefore it is biologically plausible that fetal measurements are a valid index of respiratory function.

\section{Fetal Growth Trajectory and Asthma and Allergy Outcomes}

At the time of writing, fetal growth has been related to childhood asthma outcomes in three reports from two cohorts $[7,9,51]$. Methodological differences between the two cohorts make direct comparison difficult but there are some patterns which emerge (Tables 2 and 3 ).

In a cohort recruited in Southampton [7], prospective fetal measurements were made at 10,19, and 34 weeks gestation. The same fetal measurements were made on each assessment, that is abdominal and head circumference, and this allows relative change in the same measurement to be studied. The Southampton group have focussed on relative change in growth and have not yet reported associations between absolute fetal size and childhood asthma outcomes. In their paper, Pike et al. [7] report an association between reduced head circumference growth between weeks 10 and 19 and reduced growth in abdominal girth between weeks 19 and 34 and increased wheeze at age three. Contrasting associations between fetal growth trajectory and atopy at age three years were seen; increasing abdominal growth between 10 and 19 weeks but reduced growth of the same parameter between weeks 19 and 34 were linked to increased risk for atopy. Although based on a very young group of individuals, these findings provide proof-of-concept that factors which influence antenatal growth may be important to asthma and atopy. Additionally these findings may explain the inconsistent association between asthma and atopy, for example, increased growth in early pregnancy may increase atopy but reduce asthma risk whereas faltering growth in later pregnancy may be associated with both.

A second cohort, recruited in Aberdeen $[9,51]$, was primarily designed to relate dietary exposures to childhood asthma outcomes and fetal measurements from routine first trimester "dating" and second trimester "fetal anomaly" ultrasound examinations were retrieved retrospectively. This meant that not all fetal measurements could be retrieved and different fetal measurements were made in the first and second trimester, whilst third trimester measurements were those made at delivery, that is, birth weight, length, and head circumference. Strengths of the Aberdeen cohort include relatively extended followup at ages five and ten years, inclusion of physiological measurements in childhood (e.g., spirometry), and relation of absolute fetal size to asthma outcomes. The Aberdeen group have also looked at some maternal factors which affect fetal growth $[8,51]$.

At five years of age, the main message from the Aberdeen cohort was that reduced fetal size in the first trimester was associated with increased risk for asthma symptoms and obstructed lung function regardless of later fetal growth [51]. Those who were initially short and then became larger had worse asthma outcome compared to those who were persistently large. To place fetal measurements into context, the average fetus measured $46 \mathrm{~mm}$ at ten weeks and asthma risk at five years fell by an average of $5 \%$ for each $\mathrm{mm}$ increase in size.

As part of the evaluation of the Aberdeen cohort at age five years, fetal size was related to maternal diet and smoking during pregnancy. Reduced first trimester fetal size was 
associated with reduced maternal plasma alpha tocopherol (vitamin E) suggesting that maternal diet may be important to early asthma causation [51]. The concept that vitamin E may enhance fetal lung growth is supported by work in animal models $[52,53]$ but it is also possible that increased vitamin $\mathrm{E}$ is merely an index of a generally healthier maternal diet during pregnancy and a single nutrient is not likely to have a considerable impact on fetal growth in isolation. Additional factors associated with fetal growth were male gender which was associated with increased growth during first and second trimesters [51] and maternal smoking, which was associated with reduced femur length [8]. There are a number of mechanisms whereby maternal smoking may affect fetal and lung development. Carbon monoxide, a by-product of tobacco smoking, induces fetal hypoxia [54] which may directly induce fetal growth failure. Products of tobacco smoke can indirectly affect fetal growth via a negative influence on placental function [55]; for example, nicotine causes vasoconstriction in placental vessels [55]. Maternal smoking may also reduce fetal growth by suppression of placental growth hormone and fetal insulin-like growth factor endocrine function [56]. Finally, and not to the exclusion of the previous mechanisms, maternal (and also perhaps grandmaternal smoking) may induce epigenetic in the developing fetus which could increase the unborn child's risk for asthma in later life [57].

At ten years of age, the main message from the Aberdeen cohort remained that reduced first trimester fetal size was linked to a poorer asthma outcome. Asthma outcomes were worst in those who were persistently small, best in those who were persistently large, and intermediate for those with changing growth trajectories. Additionally, the investigators demonstrated that reduced first trimester fetal size was associated with asthma which was present at both ages five and ten years but not transient or later onset asthma symptoms. Birth weight and first trimester fetal size were independently associated with reduced lung function at ten years suggesting that an element of remodelling of the respiratory system may be taking place throughout pregnancy. At ten years, but not at age five years, there was evidence that increased early growth was associated with hayfever and reduced early growth was apparently protective for eczema; there was no association between changing growth trajectory and skin prick positivity at ten years.

Putting the results of the two cohorts together is not straightforward due to the differences in methodology, analytical approach and age at follow up, however some broad conclusions can be drawn. First, changes in fetal growth trajectory size do appear to influence the risk for childhood asthma symptoms; for both cohorts reduced early growth was associated with increased asthma symptoms (Table 2). In later pregnancy, the Aberdeen group report increased asthma associated with increased growth in late pregnancy but in contrast, the Southampton group observed growth failure was associated with increased symptoms (Table 3 ). Second, early growth acceleration was associated with increased risk for atopy and atopic conditions in both cohorts; interestingly this pattern is the opposite predicted by the Barker hypothesis [10] but this was proposed for cardiovascular outcomes and not atopy. Other cohorts in Australia and Netherlands can shortly be expected to report on asthma and associated outcomes in the context of fetal growth and these will be welcome additions to the present literature. What is clear is that factors which influence fetal size and growth are important to childhood asthma outcomes and antenatal interventions may prevent childhood asthma, for example, by influencing maternal diet or smoking.

\section{References}

[1] S. Stick, "The contribution of airway development to paediatric and adult lung disease," Thorax, vol. 55, no. 7, pp. 587594, 2000.

[2] C. Remacle, F. Bieswal, and B. Reusens, "Programming of obesity and cardiovascular disease," International Journal of Obesity, vol. 28, no. 3, pp. S46-S53, 2004.

[3] C. Maschke, A. R. Franz, B. Ellenrieder, K. Hecher, A. Diemert, and P. Bartmann, "Growth after intrauterine laser coagulation for twin-twin transfusion syndrome," Archives of Disease in Childhood: Fetal and Neonatal Edition, vol. 95, no. 2, pp. F115F117, 2010.

[4] L. Ay, V. A. A. Van Houten, E. A. P. Steegers et al., "Fetal and postnatal growth and body composition at 6 months of age," Journal of Clinical Endocrinology and Metabolism, vol. 94, no. 6, pp. 2023-2030, 2009.

[5] V. Burke, L. J. Beilin, K. V. Blake et al., "Indicators of fetal growth do not independently predict blood pressure in 8-yearold Australians: a prospective cohort study," Hypertension, vol. 43, no. 2, pp. 208-213, 2004.

[6] V. A. A. van Houten, E. A. P. Steegers, J. C. M. Witteman, H. A. Moll, A. Hofman, and V. W. V. Jaddoe, "Fetal and postnatal growth and blood pressure at the age of 2 years. The generation R study," Journal of Hypertension, vol. 27, no. 6, pp. 1152-1157, 2009.

[7] K. C. Pike, S. R. Crozier, J. S.A. Lucas et al., "Patterns of fetal and infant growth are related to atopy and wheezing disorders at age 3 years," Thorax, vol. 65, no. 12, pp. 1099-1106, 2010.

[8] N. Prabhu, N. Smith, D. Campbell et al., "First trimester maternal tobacco smoking habits and fetal growth," Thorax, vol. 65, no. 3, pp. 235-240, 2010.

[9] S. Turner, N. Prabhu, P. Danielian et al., "First- and secondtrimester fetal size and asthma outcomes at age 10 years," American Journal of Respiratory and Critical Care Medicine, vol. 184, no. 4, pp. 407-413, 2011.

[10] D. J. P. Barker, "Fetal origins of coronary heart disease," British Medical Journal, vol. 311, no. 6998, pp. 171-174, 1995.

[11] M. J. Nijland, S. P. Ford, and P. W. Nathanielsz, "Prenatal origins of adult disease," Current Opinion in Obstetrics and Gynecology, vol. 20, no. 2, pp. 132-138, 2008.

[12] J. R. Ingelfinger and H. W. Schnaper, "Renal endowment: developmental origins of adult disease," Journal of the American Society of Nephrology, vol. 16, no. 9, pp. 2533-2536, 2005.

[13] J. J. K. Jaakkola, P. Ahmed, A. Ieromnimon et al., "Preterm delivery and asthma: a systematic review and meta-analysis," Journal of Allergy and Clinical Immunology, vol. 118, no. 4, pp. 823-830, 2006.

[14] A. M. Brooks, R. S. Byrd, M. Weitzman, P. Auinger, and J. T. McBride, "Impact of low birth weight on early childhood asthma in the United States," Archives of Pediatrics and Adolescent Medicine, vol. 155, no. 3, pp. 401-406, 2001. 
[15] R. Davidson, S. E. Roberts, C. J. Wotton, and M. J. Goldacre, "Influence of maternal and perinatal factors on subsequent hospitalisation for asthma in children: evidence from the Oxford record linkage study," BMC Pulmonary Medicine, vol. 10 , article 14, 2010.

[16] J. J. K. Jaakkola and M. Gissler, "Maternal smoking in pregnancy, fetal development, and childhood asthma," American Journal of Public Health, vol. 94, no. 1, pp. 136-140, 2004.

[17] K. Kindlund, S. F. Thomsen, L. G. Stensballe et al., "Birth weight and risk of asthma in 3-9-year-old twins: exploring the fetal origins hypothesis," Thorax, vol. 65, no. 2, pp. 146-149, 2010.

[18] J. Metsälä, A. Kilkkinen, M. Kaila et al., "Perinatal factors and the risk of asthma in childhood - a population-based register study in Finland," American Journal of Epidemiology, vol. 168, no. 2, pp. 170-178, 2008.

[19] L. Nepomnyaschy and N. E. Reichman, "Low birthweight and asthma among young urban children," American Journal of Public Health, vol. 96, no. 9, pp. 1604-1610, 2006.

[20] A. K. Örtqvist, C. Lundholm, E. Carlström, P. Lichtenstein, S. Cnattingius, and C. Almqvist, "Familial factors do not confound the association between birth weight and childhood asthma," Pediatrics, vol. 124, no. 4, pp. e737-e743, 2009.

[21] E. Villamor, A. Iliadou, and S. Cnattingius, "Is the association between low birth weight and asthma independent of genetic and shared environmental factors?" American Journal of Epidemiology, vol. 169, no. 11, pp. 1337-1343, 2009.

[22] X. Xu, A. B. Dailey, N. C. Freeman, B. A. Curbow, and E. O. Talbott, "The effects of birthweight and breastfeeding on asthma among children aged 1-5 years," Journal of Paediatrics and Child Health, vol. 45, no. 11, pp. 646-651, 2009.

[23] R. M. D. Bernsen, J. C. de Jongste, B. W. Koes, H. A. Aardoom, and J. C. van der Wouden, "Perinatal characteristics and obstetric complications as risk factors for asthma, allergy and eczema at the age of 6 years," Clinical and Experimental Allergy, vol. 35, no. 9, pp. 1135-1140, 2005.

[24] D. Caudri, A. Wijga, U. Gehring et al., "Respiratory symptoms in the first 7 years of life and birth weight at term: the PIAMA birth cohort," American Journal of Respiratory and Critical Care Medicine, vol. 175, no. 10, pp. 1078-1085, 2007.

[25] L. W. Doyle, M. M. H. Cheung, G. W. Ford, A. Olinsky, N. M. Davis, and C. Callanan, "Birth weight $<1501 \mathrm{~g}$ and respiratory health at age 14," Archives of Disease in Childhood, vol. 84, no. 1, pp. 40-44, 2001.

[26] K. A. Katz, S. J. Pocock, and D. P. Strachan, "Neonatal head circumference, neonatal weight, and risk of hayfever, asthma and eczema in a large cohort of adolescents from Sheffield, England," Clinical and Experimental Allergy, vol. 33, no. 6, pp. 737-745, 2003.

[27] B. N. Lærum, C. Svanes, A. Gulsvik et al., "Is birth weight related to lung function and asthma symptoms in NordicBaltic adults?” Respiratory Medicine, vol. 98, no. 7, pp. 611618, 2004.

[28] X. M. Mai, C. Almqvist, L. Nilsson, and M. Wickman, "Birth anthropometric measures, body mass index and allergic diseases in a birth cohort study (BAMSE)," Archives of Disease in Childhood, vol. 92, no. 10, pp. 881-886, 2007.

[29] B. A. Raby, J. C. Celedón, A. A. Litonjua et al., "Low-normal gestational age as a predictor of asthma at 6 years of age," Pediatrics, vol. 114, no. 3, pp. e327-e332, 2004.

[30] M. Räsänen, J. Kaprio, T. Laitinen, T. Winter, M. Koskenvuo, and L. A. Laitinen, "Perinatal risk factors for asthma in Finnish adolescent twins," Thorax, vol. 55, no. 1, pp. 25-31, 2000.
[31] T. To, J. Guan, C. Wang et al., "Is large birth weight associated with asthma risk in early childhood?" Archives of Disease in Childhood, vol. 97, no. 2, pp. 169-171, 2012.

[32] B. Xu, J. Pekkanen, J. Laitinen, and M. R. Järvelin, "Body build from birth to adulthood and risk of asthma," European Journal of Public Health, vol. 12, no. 3, pp. 166-170, 2002.

[33] S. T. Remes, S. P. Patel, A. L. Hartikainen, M. R. Jarvelin, and J. Pekkanen, "High birth weight, asthma and atopy at the age of 16 yr," Pediatric Allergy and Immunology, vol. 19, no. 6, pp. 541-543, 2008.

[34] D. D. Sin, S. Spier, L. W. Svenson et al., "The relationship between birth weight and childhood asthma: a populationbased cohort study," Archives of Pediatrics and Adolescent Medicine, vol. 158, no. 1, pp. 60-64, 2004.

[35] W. Yuan, O. Basso, H. T. Sorensen, and J. Olsen, "Fetal growth and hospitalization with asthma during early childhood: a follow-up study in Denmark," International Journal of Epidemiology, vol. 31, no. 6, pp. 1240-1245, 2002.

[36] R. J. Rona, N. C. Smeeton, P. Bustos, H. Amiga, and P. V. Diaz, "The early origins hypothesis with an emphasis on growth rate in the first year of life and asthma: a prospective study in Chile," Thorax, vol. 60, no. 7, pp. 549-554, 2005.

[37] I. M. Paul, L. Camera, R. S. Zeiger et al., "Relationship between infant weight gain and later asthma," Pediatric Allergy and Immunology, vol. 21, no. 1, pp. 82-89, 2010.

[38] J. S. Lucas, H. M. Inskip, K. M. Godfrey et al., "Small size at birth and greater postnatal weight gain: relationships to diminished infant lung function," American Journal of Respiratory and Critical Care Medicine, vol. 170, no. 5, pp. 534$540,2004$.

[39] S. Turner, G. Zhang, S. Young et al., "Associations between postnatal weight gain, change in postnatal pulmonary function, formula feeding and early asthma," Thorax, vol. 63, no. 3, pp. 234-239, 2008.

[40] S. J. Kotecha, W. J. Watkins, J. Heron, J. Henderson, F. D. Dunstan, and S. Kotecha, "Spirometric lung function in school-age children: effect of intrauterine growth retardation and catch-up growth," American Journal of Respiratory and Critical Care Medicine, vol. 181, no. 9, pp. 969-974, 2010.

[41] D. Canoy, J. Pekkanen, P. Elliott et al., "Early growth and adult respiratory function in men and women followed from the fetal period to adulthood," Thorax, vol. 62, no. 5, pp. 396-402, 2007.

[42] R. J. Hancox, R. Poulton, J. M. Greene, C. R. McLachlan, M. S. Pearce, and M. R. Sears, "Associations between birth weight, early childhood weight gain and adult lung function," Thorax, vol. 64, no. 3, pp. 228-232, 2009.

[43] H. P. Robinson and J. E. E. Fleming, "A critical evaluation of sonar "crown rump length" measurements," British Journal of Obstetrics and Gynaecology, vol. 82, no. 9, pp. 702-710, 1975.

[44] L. S. Chitty, D. G. Altman, A. Henderson, and S. Campbell, "Charts of fetal size: 2. Head measurements," British Journal of Obstetrics and Gynaecology, vol. 101, no. 1, pp. 35-43, 1994.

[45] L. S. Chitty, D. G. Altman, A. Henderson, and S. Campbell, "Charts of fetal size: 4. Femur length," British Journal of Obstetrics and Gynaecology, vol. 101, no. 2, pp. 132-135, 1994.

[46] L. S. Chitty, D. G. Altman, A. Henderson, and S. Campbell, "Charts of fetal size: 3. Abdominal measurements," British Journal of Obstetrics and Gynaecology, vol. 101, no. 2, pp. 125131, 1994.

[47] S. M. Bryan and P. C. Hindmarsh, "Normal and abnormal fetal growth," Hormone Research, vol. 65, no. 3, pp. 19-27, 2006.

[48] P. de Biasio, F. Prefumo, P. B. Lantieri, and P. L. Venturini, "Reference values for fetal limb biometry at 10-14 weeks of 
gestation," Ultrasound in Obstetrics and Gynecology, vol. 19, no. 6, pp. 588-591, 2002.

[49] J. Kivastik and P. H. Kingisepp, "Lung function in Estonian children: effect of sitting height," Clinical Physiology, vol. 15, no. 3, pp. 287-296, 1995.

[50] L. M. Gauld, J. Kappers, J. B. Carlin, and C. F. Robertson, "Prediction of childhood pulmonary function using ulna length," American Journal of Respiratory and Critical Care Medicine, vol. 168, no. 7, pp. 804-809, 2003.

[51] S. W. Turner, D. Campbell, N. Smith et al., "Associations between fetal size, maternal $\alpha$-tocopherol and childhood asthma," Thorax, vol. 65, no. 5, pp. 391-397, 2010.

[52] S. Islam, V. Narra, G. M. Coté, T. F. Manganaro, P. K. Donahoe, and J. J. Schnitzer, "Prenatal vitamin E treatment improves lung growth in fetal rats with congenital diaphragmatic hernia," Journal of Pediatric Surgery, vol. 34, no. 1, pp. 172 177, 1999.

[53] A. Azzi, R. Gysin, P. Kempná et al., "Vitamin E mediates cell signaling and regulation of gene expression," Annals of the New York Academy of Sciences, vol. 1031, pp. 86-95, 2004.

[54] P. W. Soothill, W. Morafa, G. A. Ayida, and C. H. Rodeck, "Maternal smoking and fetal carboxyhaemoglobin and blood gas levels," British Journal of Obstetrics and Gynaecology, vol. 103, no. 1, pp. 78-82, 1996.

[55] K. T. Shiverick and C. Salafia, "Cigarette smoking and pregnancy. I: ovarian, uterine and placental effects," Placenta, vol. 20, no. 4, pp. 265-272, 1999.

[56] R. Coutant, F. B. De Casson, O. Douay et al., "Relationships between placental GH concentration and maternal smoking, newborn gender, and maternal leptin: possible implications for birth weight," Journal of Clinical Endocrinology and Metabolism, vol. 86, no. 10, pp. 4854-4859, 2001.

[57] C. V. Breton, H. M. Byun, M. Wenten, F. Pan, A. Yang, and F. D. Gilliland, "Prenatal tobacco smoke exposure affects global and gene-specific DNA methylation," American Journal of Respiratory and Critical Care Medicine, vol. 180, no. 5, pp. 462-467, 2009. 


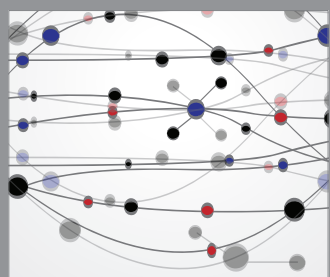

The Scientific World Journal
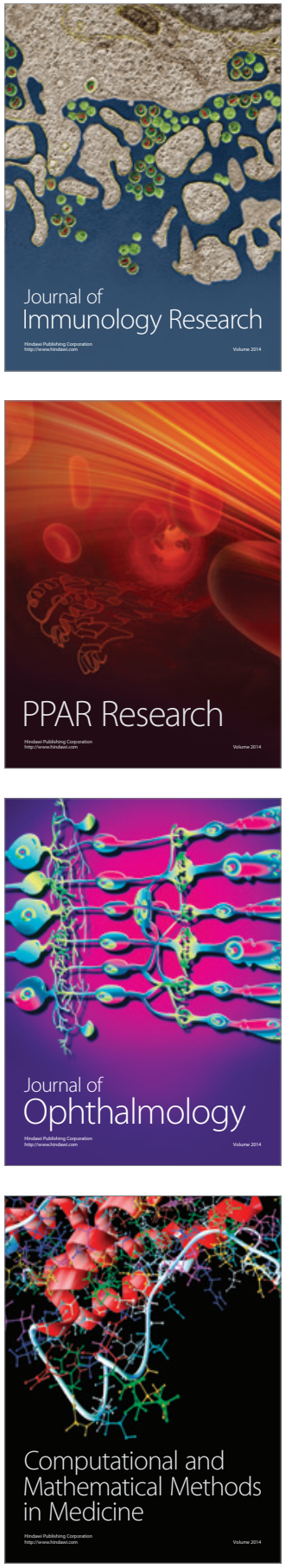

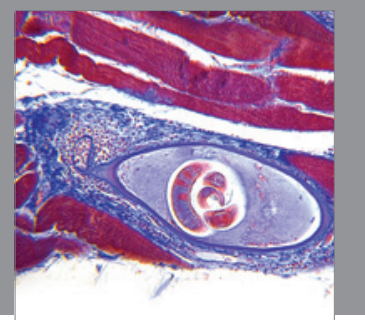

Gastroenterology

Research and Practice
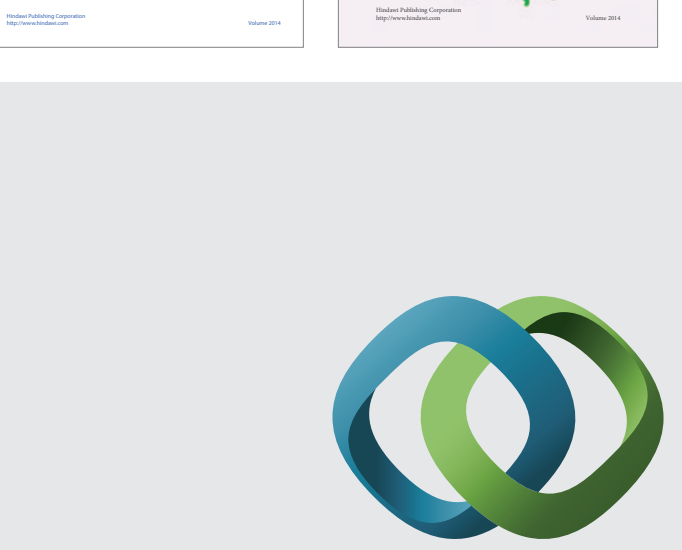

\section{Hindawi}

Submit your manuscripts at

http://www.hindawi.com
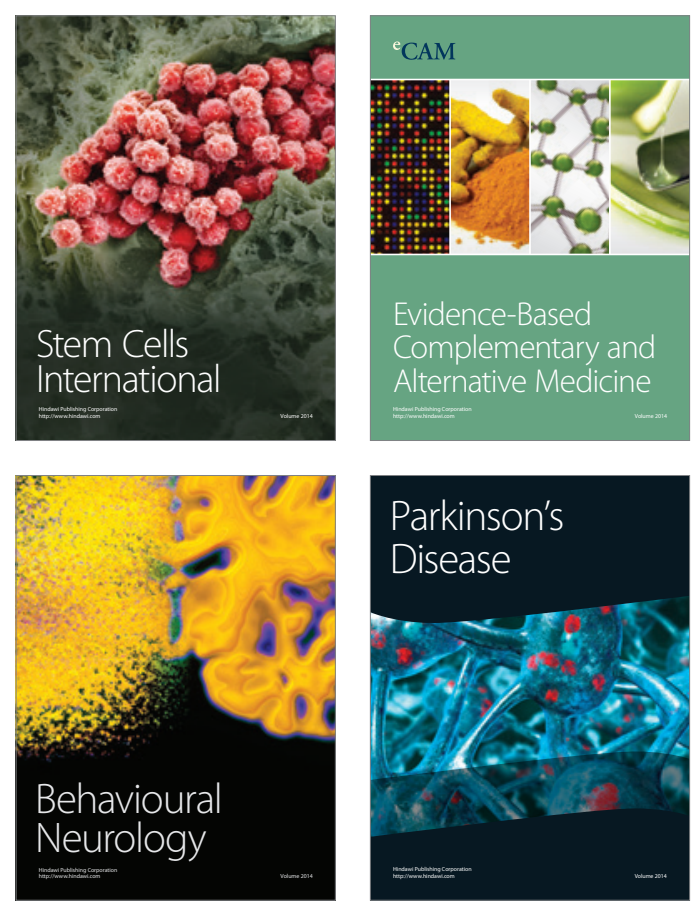

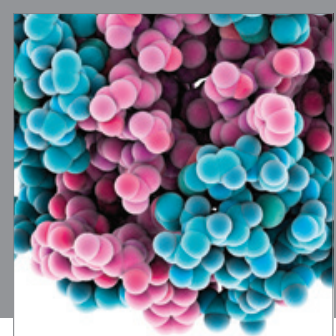

Journal of
Diabetes Research

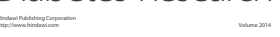

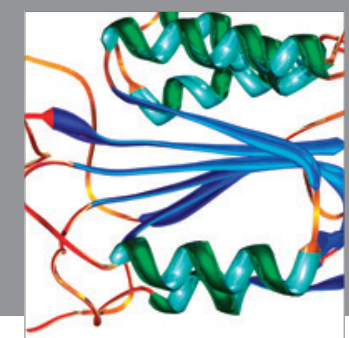

Disease Markers
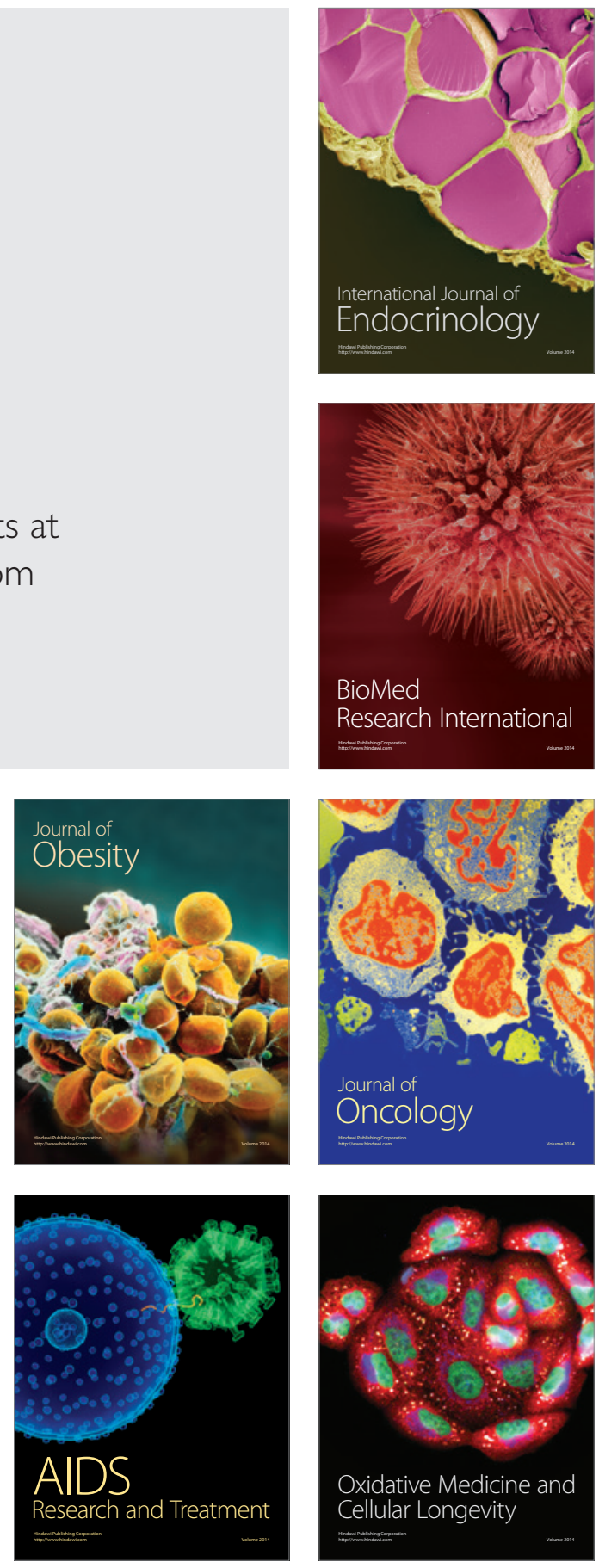